\title{
Molecular Identification of Ovine Babesia spp. in North of Iran
}

Seyed Mousa Motavalli Haghi ${ }^{1}$, Mahdi Fakhar ${ }^{2 *}$, Mehdi Sharif ${ }^{3}$, Abdolsatar Paghe ${ }^{3}$, Mitra Sharbatkhori ${ }^{4,5}$ RashidTavakoli $^{6}$, Shirzad Gholami $^{3}$

${ }^{1}$ Student Research Committee, School of Medicine, Mazandaran University of Medical Sciences Sari, Iran.

${ }^{2}$ Molecular and Cell Biology Research Center, Mazandaran University of Medical Sciences, Sari, Iran.

${ }^{3}$ Toxoplasmosis Research Center, Mazandaran University of Medical Sciences, Sari, Iran.

${ }^{4}$ Infectious Diseases Research Center, Golestan University of Medical Sciences, Gorgan, Iran.

${ }^{5}$ Department of Parasitology \& Mycology, School of Medicine, Golestan University of Medical Sciences, Gorgan, Iran.

${ }^{6}$ Veterinary Laborator, Veterinary Network of Golestan Province.

\section{Received: 3 Nov 2012}

Revised: 12 Jan 2013

Accepted: 28 Mar 2013

Corresponding Author:

Mahdi Fakhar

Molecular and Cell Biology Research

Center, Mazandaran University of

Medical Sciences, Sari, Iran

P.O Box: 48175-1665

Email: mahdif53@yahoo.com

\begin{abstract}
Background: Babesia is a blood-tissue parasite, which is transmitted by hard ticks from Ixodidae family. The parasite is the cause of babesiosis among small ruminants, cattle, human, dogs and other animals. Babesia is one of the main fatal factors among livestock in endemic regions such as Iran. The aim of this study was to identify Babesia spp infection using microscopic and molecular methods among small ruminants in Mazandaran and Golestan provinces, northern Iran, during 2011-2012.

Materials and Methods: In this study, a total of 220 sheep and goats were selected from 22 flocks in different regions of these provinces and blood samples were taken from their ears. The samples were transferred to the laboratory. Then thick and thin smears were prepared, stained with Geimsa and examined under light microscope. Standard PCR and semi nested- PCR was performed to differentiate genus of Theileria and Babesia, also identify the species of Babesia.

Results: From a total of 220 blood samples (160 sheep and 60 goats), 34 cases (15.4\%) showed Babesia infection using microscopic examination. Whereas, 11 cases $(5 \%)$ were found positive for Babesia spp using standard PCR. Also, two positive cases were showed mixed infection with Theileria spp. In addition, two microscopic negative samples were positive by PCR assay.Using semi nestedPCR, Babesia ovis $(\mathrm{n}=10)$ and B. motasi $(\mathrm{n}=1)$ were detected.

Conclusion: Our results shows ovine babesiosis is common in the Northern provinces of Iran. Moreover, Babesia ovis is the main causative agent of ovine babesiosis in northern Iran. The relatively high prevalence of Babesia infection in sheep and goats indicates the epizootic stability status of babesiosis in the northern part of Iran.
\end{abstract}

Keywords: Babesiosis; Small ruminant; Microscopic examination; PCR assay; Babesia ovis; Babesia motasi

Please cite this article as: Motavalli Haghi SM, Fakhar M, Sharif M, Paghe A, Sharbatkhori M, Tavakoli R, Gholami SH. Molecular Identification of Ovine Babesia spp. in North of Iran. Res Mol Med. 2013; 1 (1): 35-39

\section{Introduction}

In many countries, ticks and tick-borne diseases are the major impediments for the development and improvement of livestock industry (1). Babesiosis and theileriosis may cause a wide range of clinical symptoms in most domestic animals and human beings due to differences in virulence within each Babesia and Theileria species. Theileriosis and babesiosis can cause disease in the livestock with high morbidity and mortality, resulting a high economical losses worldwide (2-7). This infection is characterized by an acute febrile reaction, fever, jaundice, hemolytic anemia, hemoglobinuria and variable mortality (8-9). Diagnosis of Babesia spp and Theileria spp performs traditionally using Giemsa staining of suspicious 
blood smears and the morphology of the piroplasm in Iran, which have some technical problems and causees false morphological diagnosis and in some cases, are impossible due to carriers (10). The lack of the specificity due to cross reactivity with species of Babesia and Theileria has been observed in serological methods (10-11). Molecular techniques have been indicated suitable methods for diagnosis of babesiosis and theileriosis $(4,12)$. In this study we used molecular methods for diagnosis of Babesia spp in sheep and goats. Although ovine babesiosis is the major tick borne disease of small ruminates in Iran, there are some reports of human infection caused by Babesia microti, Babesia ovis, Babesia equi and Babesia divergenes in different part of the world (13-14), excepting Iran. Although Babesia spp and Theileria spp has been reported in animals in Iran, the prevalence of Babesia spp and Theileria spp infection has not been determined in some parts of Iran (15-17). Molecular methods such as PCR have been widely used in veterinary parasitology in recent years to identify blood protozoa (18). Due to the lack of information about the identification of Bebasia spp in sheep and goat by molecular methods in these areas, in this study we used Giemsa staining technique for microscopic detection and also as a source for the extraction of DNA for differentiation between Babesia and Theileria genus and characterize Babesia species.

\section{Materials and Methods}

This study was conducted in Mazandaran and Golestan provinces, located in the north of Iran. Twenty-two herds in these regions were chosen for the study. Each of herds had approximately 100 animals. All herds were mixed groups of sheep and goats. Ten animals from each herd, suspected to babesiosis, were randomly selected. Between 2011 to 2012, the sampling was carried out during summer. Thus, 220 blood smears were collected from animals, which demonstrated the pale mucous membranes or hyperthermia; the specimens were transferred to the parasitological laboratory of Medical University in Mazandaran for further analysis.

\section{Geimsa staining}

The fixed blood smears in methanol were stained with Geimsa in order to determine the presence of Babesia parasites. The morphological and biometrical parameters such as shape and site location of parasite in any infected erythrocyte have been considered for differential diagnosis (19-20).

\section{DNA extraction}

Babesia and theileria genomic DNA was extracted from suspected sheep and goat blood samples as described previously (19). Phenol chloroform isoamylalcohol method used for extracting DNA. Firstly, erythrocytes were slicked in lysis buffer, then $20 \mathrm{ml}$ protainase $\mathrm{k}(10 \mathrm{mg} / \mathrm{ml})$ was added, and the sample incubated for 2 hours at $56{ }^{\circ} \mathrm{C}$ to digest the proteins. Then phenol chloroform isoamyl alcohol was added and centrifuged at $13400 \mathrm{rpm}$ for $15 \mathrm{~min}$. Upper liquid phase was transferred to a new micro tube and ethanol $96 \%$ (2.5 volumes of the sample) were added and the sample were incubated for 45 min at $-20{ }^{\circ} \mathrm{C}$ and centrifuged at $13400 \mathrm{rpm}$ for 15 min. After washing with ethanol $70 \%$, finally extracted DNA air-dried, dissolved in TE buffer (10 $\mathrm{mM}$ Tris- $\mathrm{HCl} \mathrm{pH}: 8,0.1 \mathrm{mM}$ EDTA) at $55^{\circ} \mathrm{C}$, and maintained at $-4{ }^{\circ} \mathrm{C}$ for 24 hours then kept at $-20{ }^{\circ} \mathrm{C}$ until use.

\section{PCR analysis}

In order to simultaneous differentiation between Theileria and Babesia, PCR technique was used with specific primers for Babesia and Theileria spp. (Table 1) derived from flanking part of hyper variable region of 18srRNA.The PCR products of Theileria spp. and Babesia spp. were 420-430 bp and 389-402 bp, respectively $(7,21)$. The difference of approximately $30 \mathrm{bp}$ in the length of PCR products of the two parasites is easily revealed in $1.5 \%$ agarose gel (21). The PCR was performed in a total volume of $25 \mu \mathrm{l}$ including $5 \mu \mathrm{l}$ of DNA template, $1 \mathrm{X}$ PCR buffer, $0.1 \mathrm{U}$ Taq polymerase, $0.5 \mu \mathrm{l}$ of each primer $\left(\mathrm{P}_{1} / \mathrm{P}_{2}, 20\right.$ $\mathrm{mM}), 125 \mu \mathrm{M}$ of each deoxadenosine triphosphate, deoxythymidine triphosphate, deoxycytidine triphosphate and deoxyguanosine triphosphate (fermentas) and $1.5 \mathrm{mM} \mathrm{MgCl} 2$ in an automatic DNA Thermocycler (Bio-Rad); with the following program: $5 \mathrm{~min}$ at $95{ }^{\circ} \mathrm{C}$ to denature double strand DNA, 38 cycles of $45 \mathrm{~s}$ at $94{ }^{\circ} \mathrm{C}, 45 \mathrm{~s}$ at $56^{\circ} \mathrm{C}, 45 \mathrm{~s}$ at $72{ }^{\circ} \mathrm{C}$ and a final extension step for $10 \mathrm{~min}$. The amplified products were resolved by $1.5 \%$ agarose gel electrophoresis and stained with ethidium bromide for visual detection by ultraviolet transillumination.

\section{Semi nested-PCR}

In order to differential diagnosis of Babesia spp, semi nested- PCR were carried out on the PCR products employing $\mathrm{P}_{2}$ primer as an antisense and $\mathrm{P}_{3}, \mathrm{P}_{4}$ as sense primers that derived from V4 region of $18 \mathrm{~s}$ rRNA (22) (Table1). This technique was performed in a total volume of $25 \mu \mathrm{l}$ including $5 \mu \mathrm{l}$ of PCR product, one time PCR buffer, $0.1 \mathrm{U}$ Taq polymerase dNTPs (each one, $1.5 \mathrm{mM} \mathrm{MgCl} 2$ in an automated Thermocycler (Bio-Rad) with the following program: 5 min incubation at $95^{\circ} \mathrm{C}$ to denature double- strand DNA, 35 cycles of $1 \mathrm{~min}$ at $94^{\circ} \mathrm{C}, 1 \mathrm{~min}$ at $60^{\circ} \mathrm{C}, 1$ min at $72{ }^{\circ} \mathrm{C}$ and finally, PCR was completed with 
the additional extension step for $10 \mathrm{~min}$. The PCR products were analyzed on $1 \%$ agarose gel in $1 \mathrm{X}$
TBE buffer and visualized using ethidium bromide and an UV illuminator.

Table1. The sequences of primers in PCR for Babesia and Theileria and primers of semi nested-PCR for B.ovis and B. motasi.

\begin{tabular}{lcc}
\hline PCR product $(\mathbf{b p})$ & Nucleotide sequences & Name of primer \\
\hline $426-430$ (Theileria) & 5 CACAGGGAGGTAGTGACAAG 3 & 18S rRNA gene \\
$389-402$ (Babesia) & 5 AAGAATTTCACCTATGACAG 3 1 & 18S rRNA gene \\
186 & 5 GTCTGCGCGCGGCCTTTGCG 3 & B. ovis-sense \\
205 & 5 CGCGATTCCGTTATTGGAG 3 & B. motasi-sense \\
\hline
\end{tabular}

\section{Results}

34 from a total of 220 sheep (160) and goats (60) samples (15.45\%) showed Babesia infection in the microscopic examination (Figure. 1)

The result of the standard PCR showed 5\% $(n=11)$ positive for Babesia genus that two cases were indicated mixed infection with Theileria spp. The PCR products of Babesia and Theileria were 389-402 bp and 426-430 bp, respectively (Figure. 2). Two cases obtained positive by molecular method but were negative by microscopic method. Babesia infection was $1.81 \% \quad(n=4)$ and $3.1 \% \quad(n=7)$ in Mazandaran and Golestan provinces, respectively. Moreover, the species of Babesia in all positive cases were found Babesia ovis $(\mathrm{n}=10)$ and Babesia motasi $(n=1)$ using semi nested- PCR .

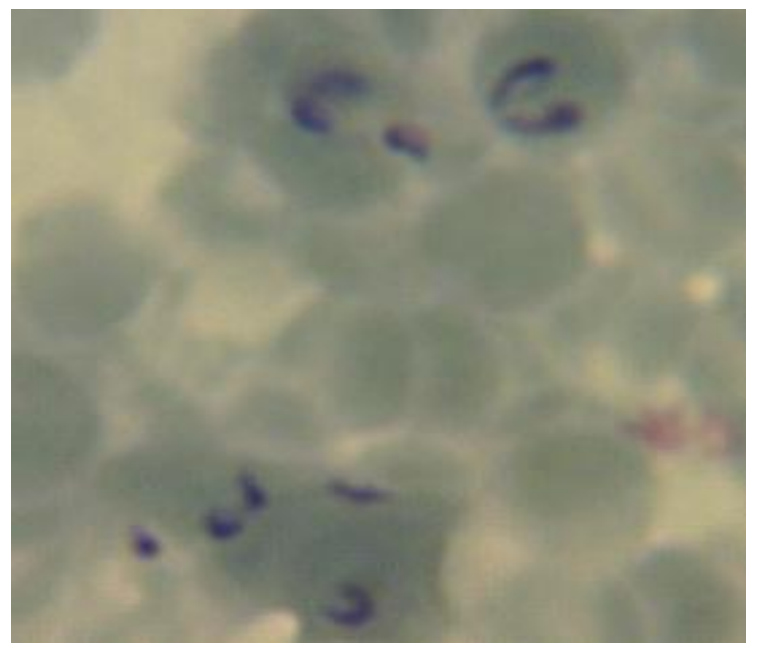

Figure 1. peripheral blood smear from Babesia infected sheepstained with Giemsa showing large Babesia spp.

\section{Discussion}

One of the most important diseases in small ruminants is the infection with protozoan parasites Theileria and Babesia, which cause annually high economic losses worldwide (22). Among a total of 220 collected samples, Babesia and Theileria were detected in 5\% and $24 \%$, respectively that is in concordance with a similar research, performed by Altay et al, in Turkey that reported high infection of Theileria (23). Our data showed that Babesiosis and Theileriosis are enzootic among livestock in investigated regions. Babesiosis and Theileriosis are important diseases in the livestock with high morbidity and mortality, resulting a high economical losses worldwide $(2,24)$. A successful and healthy economy in livestock farming requires a serious management of livestock health, which is achievable through accurate and early diagnosis and therapy.

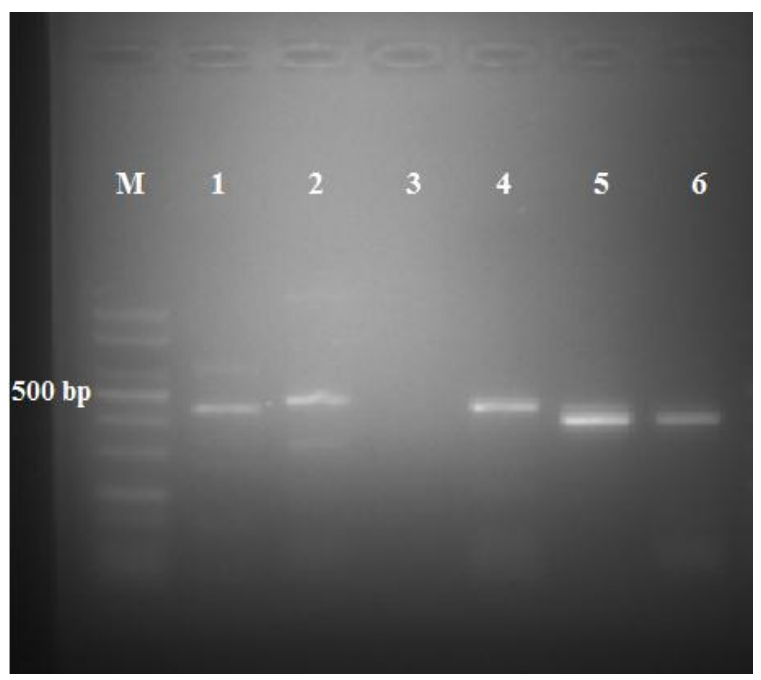

Figure 2. PCR products were analyzed with primers 1,2 specific for 18s rRNA gene of Babesia and Theileria; line 1-Positive control for Babesia. line5,6 Babesia samples.Line 2-positive control for Theileria.line 4 Theileria samples.Line3- Negative control. Line M- Marker 100bp

In this study standard PCR of $18 \mathrm{~s}$ rRNA showed Babesia and Theileria genera and semi nested- PCR detected B. ovis $(3.6 \%)$ and B. motasi $(1.4 \%)$ that had previously reported to occur in Iran $(15,25,26)$. Standard PCR showed mixed infection with Babesia and Theileria in two sheep. Previously, Sadeghi Dehkordi et al reported mixed infection of Babesia and Theileria in Iran (27). Detection of Babesia ovis and $B$. motasi using semi nested- PCR method, 
revealed that $B$. ovis was more prevalent than B. motasi among sheep in Mazandaran and Golestan provinces. Our results confirm the findings of the study was conducted in Khorasan in north eastern Iran regarding distribution of $B$. ovis and B. motasi in the province (25). In different areas of Iran, B. ovis considered as a main causative agent of sheep babesiosis by molecular techniques. In this study, two cases were positive using molecular methods and negative by microscopic method. -This finding was reported in a previous study and emphasized that sensitivity and specificity of molecular method is higher than microscopic method for determination Babesia spp and Theileria spp (27). The percentage of sheep infected with $B$. motasi and simultaneously exhibiting clinical signs linked to high parasitemia was higher than that of sheep infected with $B$. ovis. This was a predictable result in which the pathogenicity of $B$. motasi is generally accepted to be higher than of the B. ovis (28-29).B. ovis was reported from Southern Europe, former Soviet States, Northern Africa, Middle East and Asia (30-31). In our study, B. ovis was more prevalent $(3.6 \%)$ than B. motasi (1.4\%) among small ruminants in Golestan and Mazandaran provinces that is in concordance with other parts in Iran (31-34). It causes anemia, icterus and hemoglobinuria in sheep. Mortality rate can reach $25 \%-30 \%$ in sick animals, without effective treatment. Although, the role of Rhipicephalus bursa in transmission of ovine babesiosis has not been investigated in Iran, but it has been considered the main vector for both $B$. ovis and B. motasi (34-35). However, there are unpublished data in Iranian Veterinary Organization based on collected data from local laboratory in the country, but these are not quite significant and suitable for judgment. In conclusion, the relatively high prevalence of Babesia infection in livestock (mainly ovine babesiosis) indicates the epizootic stability status of babesiosis in the investigated areas and will pose a risk for inhabitants (mainly farmers) there. As a whole, our data provide valuable information regarding the epidemiology of babesiosis in small ruminants in the northern regions of Iran which will likely be very favorable for management and control programs of this disease.

\section{References}

1. Ghaemi P, Hoghoogh-Rad N, Shayan SH, Eckert B. Detection of Theileria orientalis in Iran by semi-nested PCR. Parasitol Res 2012; 528-31. PMID: 22177334

2. Ahmed J, Yin H, Schnittger L, Jongejan F. Ticks and tick-borne diseases in Asia with special emphasis on China. Parasitol Res. 2002; 88, 51-5. PMID: 12051612

3. Barnett SF. Economical aspects of protozoal tick-borne diseases in livestock in parts of the world other than Britain. Bull Off Int Epiz. 1974a; 81 (1-2):183-96.
4. Barnett SF. Economical aspects of tick-borne disease control in Britain. Bull Off Int Epiz. 1974b; 81 (1-2):167-82.

5. Mehlhorn H, Schein E. The piroplasms: life cycle and sexual stages. Adv Parasitol.1984; 23:37-103. PMID: 6442536

6. Mehlhorn H, Schein E, Ahmed JS. Theileria. In: Kreier JP (ed) Parasitic protozoa. Academic Press, San Diego. 1994; 7: 217-304.

7. Shayan, P, Rahbari S. Simultaneous differentiation between Theileria spp and Babesia spp on stained blood smear using PCR. Parasitol Res. 2005; 97: 281-6. PMID: 16007464

8. Zajac,Anne M. Conboy, Gary A. Veterinary clinical parasitology, Wiley-Blackwell Oxford, UK.2006; 7.

9. Bock R, Jackson L, de Vos A, Jorgensen W. Babesiosis of cattle. Parasitol. 2004; 129: 247-69.

10. Tavasoli M, Rahbari S. Seroepidemiological survey on Babesia ovis in different geographical region of Iran. Vet $\mathbf{J}$ Tehran Univ. 1998; 53 (3, 4):55-59.

11. Persing DH, Herwaldt B L, Glaser C. Infection with a Babesia like organism in northern California. N Engl J Med.1995; 2332 (5):298-303. PMID: 7816065

12. Bai Q, Liu G, Liu D. Isolation and preliminary characterization of a large Babesia sp. From sheep and goat in the eastern part of Gansu province, China. Parasitol Res. 2002; 88:16-21. PMID: 12051600

13. Vannier E, Gewurz BE, Krause PJ. Human babesiosis, Infectious Disease Clinics of North America. 2008; 22 (3); 469-88. PMID: 18755385

14. Kalani H, Fakhar M, Pagheh AS. Review on statues Babesiose and Theilerios in Iran and scattering vector ticks. Iranian Med Microbiol J. 2011; 59-71.

15. Hashemi-Fesharaki R. Tick-borne disease of sheep and goats and their related vectors in Iran. Parasitolo.1997; 39: 115-7. PMID: 9530694

16. Hosseni HS. Parasitic infections of domesticated animals. $2003 ; 61-65$.

17. Ziapour SP, Esfandiari B, Youssefi MR. Study of the prevalence of Babesiosis in domesticated animals with suspected signs in Mazandaran Province, north of Iran, during 2008. J of Anim Vet Adv. 2011; 10(6): 712-14.

18. Noaman V. A molecular study on Theileria and Babesia in cattle from Isfahan province, Central Iran. J Parasitol Dis. 2013; 37(2): 208-10. PMID: 24431572

19. Almeria S, Castella J, Ferrer D. Bovine piroplasma in Minorca (Balearic Island, Spine): a comparison of PCR based and light microscopy detection. Vet Parasitol. 2001; 99(3):249-59. PMID: 11502372

20. Habela M, Reina D, Nieto C. Navarrete I. Isolation and identification of Babesia ovis in Extremadura (Spain). Vet Parasitol. 1990; 35(3): 233-8. PMID: 1693020

21. Shayan P, Hooshmand E, Nabian S, Rahbari S. Biometrical and genetical characterization of large Babesia ovis. Parasitol Res. 2008; 103(1): 217-21. PMID: 18386062 
22. Shayan P, Rahbari S. Differentiation of sheep Theileria spp. and Babesia spp. by Polymerase Chain Reaction. J Vet Res. 2007; 62(3):250-60.

23. Altay k, Aktas M, Dumanli N. Theileria Infections in Small Ruminants in the East and Southeast Anatolia, Türkiye Parazitol Dergisi. 2007; 31 (4): 268-71. PMID: 18224614

24. Soulsby EJ. Helminths, arthropods and protozoa of domesticated animals. Helminths, arthropods and protozoa of domesticated animals. 1968.

25. Razmi G.R, Naghibi A, Aslani MR, Fathivand M, Dastjerdi K. An epidemiological study on ovine babesiosis in the Mashhad suburb area, province of Khorasan, Iran. Vet Parasitol. 2002; 108(2): 109-15. PMID: 12208039

26. Fakhar M, Hajihasani A, Maroufi S, Alizadeh H, Shirzad H, Piri $\mathrm{F}$, et al. An epidemiological survey on bovine and ovine babesiosis in Kurdistan Province, western Iran. Trop Anim Health Prod. 2012; 44(2):319-22. PMID: 22109588

27. Dehkordi zs, Zakeri S, Nabian S, Bahonar A, Ghasemi F, Noorollah F, et al. Molecular and Biomorphometrical Identification of Ovine Babesiosis in Iran. Iran J Parasitol. 2010; 5(4):21-30. PMID: 22347262

28. Razmi GR, Naghibim A, Aslani MR, Dastjerdi K, Hossieni H. An epidemiological study on Babesia infection in small ruminants in Mashhad suburb, Khorasan Province, Iran. Small Ruminant Res. 2003; 50(1):39-44.

29. Taylor MA, Coop RL, Wall RL. Vet Parasitol, $3^{\text {rd }}$ edition, Oxford; Blackwell, UK; 2007.

30. Razmi G.R, Najarnejad V, Rashtibaf M. Determination the frequency of Ixodid ticks on the sheep in Khorasan Razavi province, Iran. Arch Razi Inst. 2011; 66 (2): 129-132.

31. Razmi G.R, Nouroozi E. Transovarial Transmission of Babesia ovis by Rhipicephalus sanguineus and Hyalomma marginatum. Iran J Parasitol. 2010 5(3): 35-9. PMID: 22347253

32. Razmi G, Pourhosseini M, Yaghfouri S, Rashidi A, Seidabadi M. Molecular detection of Theileria spp. and Babesia spp. in sheep and ixodid ticks from the northeast of Iran. J Parasitol. 2013; 99 (1):77-81. PMID: 22924924

33. Anwar M. Geographical distribution of protozoan blood parasites of domestic animal in Iran. Bull Off Int Epizoot. 1974; 81:793-8.

34. Rak H. Tick-borne diseases and their vectors in Iran. In: Wilde, JKH. Tickborne diseases and their vectors. Edinburgh, University Press. 1978; P. 163-166.

35. Rafyi A, Niak A, Rak H. Bref compte Rendu sur les tiques, les maladis transmises par les tiques ET le controle de ces parasite en Iran. Bull Off Int Epizoot. 1974; 81: 1-7. 